\title{
Strategic Interactions Between Fishermen And A Coastal Nation
}

\author{
Yoav Wachsman, (E-mail: yoav@ coastal.edu), Coastal Carolina University
}

\begin{abstract}
Coastal nations can impose conditions of use on foreign fishermen that operate in their Exclusive Economic Zone. We develop a game-theoretical model in which a fishery owner maximizes the revenue that it collects from fishermen that operate in its EEZ by charging them a fishing fee. We find that if the number of fishermen is exogenous the owner selects a fee that is higher than socially optimal. On the other hand, if the owner can choose the number of fishermen, it does not restrict entry to the EEZ and selects a fee that maximizes net return. Alternatively, the owner can use a two-tier tariff to extract all the net return from the fishery.
\end{abstract}

\section{Introduction}

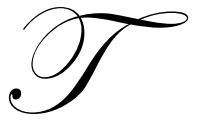

he Extended Fisheries Jurisdiction (EFJ), adopted in 1982 by the United Nations Conference on the Law of the Sea, established the formation of 200-mile Exclusive Economic Zones (EEZ). It is now recognized that coastal nations have ownership rights over the 200 nautical miles adjacent to their shores. ${ }^{1}$ Accordingly, a coastal nation can "impose terms and conditions of access upon Distant Water Fishing Nations (DWFN) seeking to enter the coastal state's EEZ (Clarke and Munro, 1991)."

The EFJ was adopted in order to accomplish two objectives. The first objective is to help protect the world's marine resources by clearly defining property rights over previously unregulated fisheries. When ownership rights over a fishery are poorly defined, fishermen have the incentive to overexploit the stock because they do not account for the external costs of their exploitation on other users (Gordon, 1954; Levhari and Mirman, 1980; Kaitala and Munro, 1993; and elsewhere). Whereas, a single owner has the incentive to optimally manage a fishery (Scott, 1955). The second objective is to provide a source of revenue for coastal nations, particularly developing nations that have few other economic resources (Ishimine, 1978).

Indeed, thanks to the EFJ many of the world's most prolific fisheries are now under the ownership of developing nations (Gopalakrishnan, 1989). Yet, many of these developing nations lack the necessary technology to efficiently exploit their marine resources. Consequently, many developing nations permit foreign fishermen to harvest fish from their fisheries and then charge the fishermen a fishing fee on the harvest that they remove. For example, a group of island nations in the South West Pacific Ocean known as Parties to the Nauru Agreement collect 5\% of the revenue that foreign fishermen earn from harvesting fish within their EEZ and contiguous areas (Campbell, 1996). ${ }^{2}$

We use non-cooperative game theory to model how a coastal nation maximizes the revenue that it collects from fishermen that operate in its EEZ. This paper is one of the few papers that model the strategic interactions between a coastal nation and the fishermen that it admits into its EEZ. We show that when the number of fishermen is exogenous, the coastal nation will select a fee that is higher than socially optimal, thus inducing fishermen to exert less effort than is socially optimal. On the other hand, if the coastal nation can determine the number of fishermen it can simultaneously maximize its revenue and the net return from the fishery by not restricting entry to the fishery and charging the socially optimal fishing fee. To the best of our knowledge, this is the first paper to consider the number of fishermen that the coastal nation admits into its fishery as a policy variable of the coastal nation. Alternatively, the coastal nation can use a two-tier tariff to simultaneously maximize its revenue and the net return 
from the fishery. We are not aware of any other paper that examines the strategic interactions between a group of fishermen and a coastal nation that considers the possibility of a two-tier tariff.

Several authors have looked at the strategic interactions amongst fishermen in an unregulated, international fishery (Levhari and Mirman, 1980; Fischer and Mirman, 1996; Dockner et al, 1989; Ruseski, 1998; and elsewhere). All of these authors conclude that the fishermen will over-fish the stock. But only a few authors examined the strategic interactions between a coastal nation and the foreign fishermen that operate in its EEZ. Charles (1986) develops a model in which a coastal nation divides a fixed Total Allowable Catch between a domestic fleet and a foreign fleet. He shows that the coastal nation may allow both fleets to operate in its fishery, allow only one of the fleets to operate, or cause both of the fleets to disinvest their capital, depending on the domestic and the foreign resource rents. Charles, however, assumes that both the fishing fee and the number of fishermen are exogenous, when in reality a coastal nation can control both of these variables.

Clarke and Munro (1987) examine a principal-agent model in which a coastal nation charges a single DWFN a fishing fee. Clarke and Munro (1991) generalize their model by considering the possibility that the coastal nation and the DWFN discount future returns from the fishery at different rates. They find that the coastal nation can increase its discounted net revenue from the fishery by simultaneously using a tax on harvest and a tax or subsidy on effort instead of only a fishing fee. Raissi (2001) extends Clarke and Munro's model by considering a case in which a nation permits both a foreign fisherman and a domestic fisherman with an inferior technology to operate in its fishery. Both Clarke and Munro and Raissi conclude that the coastal nation is generally unable to simultaneously maximize the discounted net return from the fishery and its own discounted net revenue - our paper disputes this claim.

All three aforementioned papers do not allow the coastal nation to determine the number of fishermen and assume that the coastal nation can tax effort, which is unlikely since effort is multivariate and difficult to observe. Additionally, none of these researchers consider the possibility that the coastal nation can use a two-tier tariff by charging each fisherman an entry fee (i.e., a license fee) and an additional fishing fee. Accordingly, these researchers wrongfully conclude that the costal nation cannot simultaneously maximize its revenue and the net return from the fishery. We show that, at least in theory, the costal nation is able to do both either by allowing free entry into the fishery or by using a two-tier tariff.

The paper proceeds as follows. In section 2 we assume that the number of fishermen, $\mathrm{n}$, is finite and exogenous. We find that there exists a fishing fee that maximizes the coastal nation's revenue, but that the fee is generally higher than socially optimal. In section 3 we analyze other policies that the coastal nation can utilize in order to extract all the net return from the fishery. First, we examine the case in which the coastal nation does not charge an entry fee but can choose both the number of fishermen and the fishing fee. We show that the best solution for the coastal nation is to not place any restrictions on entry to the fishery and to select the socially optimal fishing fee. Alternatively, the coastal nation can admit a finite number of fishermen and use a two-tier tariff to extract all the net return from the fishery. In section 4 we discuss what the optimal number of fishermen is and draw conclusions.

\section{A Model with a Single Fee and a Fixed Number of Fishermen}

Consider a fishery that is exploited by $\mathrm{n}$ identical foreign fishermen. For tractability, we assume that $\mathrm{n}$ is continuous. The fishermen may belong to a single or to several different Distant Water Fishing Nations (DWFN). We shall assume that the fishermen's governments do not regulate their behavior and that no collaboration exists amongst the fishermen. The fishery is assumed to be under the control of a single coastal nation that we shall refer to as the fishery owner.

In this section we shall assume that the number of fishermen is finite and exogenous. We also assume that the coastal nation does not charge an entry fee. These assumptions are comparable to the ones made by Clarke and Munro (1987, 1991). In the following section we shall relax these assumptions and examine what happens if the coastal nation determines the number of fishermen or imposes an entry fee. 
The strategic interactions amongst the fishermen and between the fishermen and the owner are modeled using non-cooperative game theory as a two-stage game. In the first stage of the game the owner selects a fishing fee. The fishing fee, $r$, denotes the percent of the revenue from the harvest that is caught in the fishery which the owner retains for itself. In the second stage of the game the fishermen, having observed the fishing fee, simultaneously choose their levels of effort in order to maximize their profit.

We begin by solving for the equilibrium efforts, the levels of effort that the fishermen will select in subgame perfect Nash equilibrium. Subgame perfection in the second stage of the game occurs when every fisherman chooses the profit-maximizing level of effort given the fishing fee and the levels of effort chosen by the other fishermen. Subgame perfection in the first stage of the game occurs when the owner selects the fee that maximizes its revenue after computing the equilibrium efforts as a function of $r$.

Since Schafer's (1957) seminal work on the exploitation of fish, it is common to assume that the size of a fish stock, $\mathrm{x}$, grows according to a stock dependent growth function. The change in the size of the stock at a given point in time, $d x / d t$, equals the stock's natural growth rate, $G(x)$, minus the sum of the harvests collected. Let $h_{i}$ denote the harvest of fisherman $i$.

$$
\frac{d x}{d t}=G(x)-\sum_{i=1}^{n} h_{i}
$$

We shall assume, as other authors have (e.g., Clarke and Munro, 1991; Ruseski, 1998; and Raissi, 2001), that the stock grows according to a linear logistic function.

$$
G(x)=\gamma x\left(1-\frac{x}{K}\right)
$$

$\gamma$ is the stock's intrinsic rate of growth, which equals the birth rate of the stock minus its mortality rate, and $\mathrm{K}$ is the carrying capacity of the fishery. The carrying capacity is the largest stock size that the fishery can sustain. If the fishery is not commercially exploited the size of the stock would eventually converge to the carrying capacity of the fishery. As commonly assumed in the literature, each fisherman harvests fish according to a Catch Per Unit of Effort (CPUE) production function. A CPUE production function implies that the portion of the stock that each fisherman harvests per unit of effort is constant. Let $\mathrm{e}_{\mathrm{i}}$ represent the effort exerted by fisherman $\mathrm{i}$ and e be a vector of efforts, e $=\left[\mathrm{e}_{1}, \ldots, \mathrm{e}_{\mathrm{i}}, \ldots, \mathrm{e}_{\mathrm{n}}\right]$.

$$
\mathrm{h}_{\mathrm{i}}(e)=\begin{array}{ll}
q x e_{i} & \text { if } e_{i}<\frac{1}{n q} \\
x / n & \text { otherwise }
\end{array}
$$

$\mathrm{q}$ is the catchability coefficient, $0<\mathrm{q}<1$. For simplicity, we assume that q does not depend on the size of the stock and that it is identical for all the fishermen, which suggests that the fishermen are using an identical technology. ${ }^{3}$ Substituting (0.1) and (0.2) into (0.3):

$$
\frac{d x}{d t}=\gamma x\left(1-\frac{x}{K}\right)-q x \sum_{i=1}^{n} e_{i}
$$

The size of the stock reaches a steady state when $\mathrm{dx} / \mathrm{dt}=0$. We determine the steady-state stock, $\bar{x}(e)$, by setting (0.4) equal to zero and solving for $\mathrm{x}$. 


$$
\bar{x}(e)=K\left(1-\frac{q}{\gamma} \sum_{i=1}^{n} e_{i}\right)
$$

We assume, as Ruseski (1998) does, that fishermen maximize their profits in steady state, which occurs when the size of the stock reaches a biologically stable equilibrium. Ruseski's framework requires assuming that agents do not discount future returns, as we shall assume in this paper. This assumption greatly simplifies the analysis and allows us to focus on the strategic interactions of the agents. ${ }^{4}$ We feel justified using a static model rather than a dynamic model, in which the coastal nation can choose a different fishing fee in each period, because "long-term cooperative agreements between coastal and distant water nations are more likely to involve simple fixed-rate royalty schemes, in order to provide stability to the arrangement (Charles, 1986)." Clarke and Munro and others who use more dynamic models examine models with only one or two fishermen and make other simplifying assumptions.

Each fisherman attempts to maximize the profit that it earns when the size of the stock reaches a steady state by independently choosing a level of effort. Fishermen know what the fishing fee is before making their decision, but can not observe the levels of effort that are chosen by other fishermen. For simplicity, we assume that the total harvest extracted from the fishery is too small to influence the price of the species, $\mathrm{p}$. We also assume that fishermen face a constant and identical marginal cost of effort, c. ${ }^{5}$ Fisherman i will attempt to:

$$
\operatorname{Max}_{e_{i}} \Pi_{i}=(1-r) p \times q \bar{x}(e) e_{i}-c e_{i}
$$

The first term on the right-hand side of (0.6) is the fisherman's revenue, which equals the fisherman's harvest in steady state times the price of the species multiplied by the portion of the revenue that the fisherman retains after paying the fishing fee, $(1-r)$. The second term is the cost of effort. Since all the fishermen are identical by assumption, the owner has no reason to charge each fisherman a different fishing fee. Each fisherman takes into account the effect of its own effort on the steady-state stock but must take the effects of other the fishermen's efforts as given. Rewriting the objective function of fisherman i by substituting $(0.5)$ for $\bar{x}(e)$ :

$$
\operatorname{Max}_{e_{i}} \Pi_{i}=(1-r) b\left(1-\frac{q}{\gamma} e_{i}-\frac{q}{\gamma} \sum_{j \neq i}^{n} e_{j}\right) e_{i}-c e_{i} \text { where } b=p q K
$$

$b$ is the marginal revenue of effort. It represents the increase in revenue that occurs when effort increases by one unit but the steady-state stock does not change. Since the fishermen are identical they must select the same effort in subgame perfect Nash equilibrium. Let $\hat{e}_{j}$ represent the effort that any other fisherman $j, j=1, \ldots, n, j \neq i$, selects in equilibrium. We derive the reaction function of fisherman i to the effort levels chosen by all other fishermen, by rearranging the first-order conditions of fisherman i's objective function.

$$
e_{i}\left(\hat{e}_{j}\right)=\frac{1}{2}\left[\frac{[(1-r) b-c] \gamma}{(1-r) b q}-(n-1) \hat{e}_{j}\right]
$$

Observe that when other fishermen increase their effort fisherman i's best response is to reduce his effort. By symmetry, in equilibrium the effort level that fisherman i selects must be the same as the effort level selected by any other fisherman. We obtain the effort level that any of the $n$ fishermen would select in subgame perfect Nash equilibrium by substituting $\mathrm{e}_{\mathrm{i}}$ for $\hat{\mathrm{e}}_{\mathrm{j}}$ in (2.8) and solving for $\mathrm{e}_{\mathrm{i}}$. 


$$
e_{i}(r)=\frac{\gamma}{(n+1) q}\left(\begin{array}{cc}
\left.1-\frac{c}{(1-r) b}\right) & \text { if }(1-r) b>c \\
0 & \text { otherwise }
\end{array}\right.
$$

$e_{i}(r)$ is the equilibrium effort of fisherman $i$, the effort that fisherman i selects in subgame perfect Nash equilibrium given $r$. We write the equilibrium efforts as a function of $r$ because the fishing fee is a policy variable that is chosen by the owner. An increase in the intrinsic rate of growth, the carrying capacity of the fishery, or the price of the species will increase the equilibrium efforts of all the fishermen. An increase in the marginal cost of effort, the number of fishermen that operate in the fishery or the fishing fee will reduce the equilibrium efforts of all the fishermen. The effect of the catchability coefficient on the equilibrium efforts depends on the values of the parameters. We shall assume that if the owner does not charge a fishing fee then the fishery is exploitable, which means that the marginal revenue of effort, $b$, is larger than the marginal cost of effort, $c$. Let $r_{\text {MAX }}$ represent the highest fee that the fishery owner can charge without making the fishery unprofitable for commercial exploitation. From $(0.9)$ the fishermen will choose a positive level of effort as long as $(1-r) b>c$. Thus:

$$
r_{M A X}=1-\frac{c}{b}
$$

Figure 1 shows the reaction functions of the fishermen in a fishery with only two fishermen. As illustrated, an increase in the fishing fee from $r^{0}$ to $r^{1}$ shifts the reaction functions of both fishermen inwards. The equilibrium effort of fisherman 1 decreases from $\mathrm{e}_{1}\left(\mathrm{r}^{0}\right)$ to $\mathrm{e}_{1}\left(\mathrm{r}^{1}\right)$ and the equilibrium effort of fisherman 2 decreases from $\mathrm{e}_{2}\left(\mathrm{r}^{0}\right)$ to $\mathrm{e}_{2}\left(\mathrm{r}^{1}\right)$.

If $r$ were equal to or larger than $r_{\mathrm{MAX}}$, then the profit-maximizing effort of every fisherman would be zero. It makes no sense for the owner to choose a fee that is equal to or is higher than $r_{\text {MAX }}$ since the fishery will not be exploited; therefore, $r$ must be smaller than $r_{\text {MAX }}$. Note from (0.9) that as long as the fishing fee is below $r_{\text {MAX }}$, then any fisherman will exploit the fishery regardless of the number of fishermen that already operate in the fishery. Since the fishermen's equilibrium efforts are identical by symmetry, the total equilibrium effort, E(r), must equal $n \times e_{i}(r)$.

$$
E(r)=\frac{n \gamma}{(n+1) q}\left(1-\frac{c}{(1-r) b}\right)
$$

Next, we solve for the steady-state stock that the fishery converges to in subgame perfect Nash equilibrium. This stock size is often referred to as the bionomic equilibrium stock since it is the biologically stable size that the stock reaches when the fishermen that utilize the fishery achieve an economic equilibrium. Substituting (0.11) into (0.5):

$$
\bar{x}(r)=K\left[1-\frac{n}{n+1}\left(1-\frac{c}{(1-r) b}\right)\right]
$$

The harvest that each fisherman removes from the fishery when the fishery reaches a bionomic equilibrium, $\mathrm{h}_{\mathrm{i}}(\mathrm{r})$, is found by substituting $(0.12)$ and $(0.9)$ into the CPUE production function, equation (0.3). Define the bionomic equilibrium harvest, $\mathrm{H}(\mathrm{r})$, as the total harvest that will be removed from the fishery when the fishery reaches a bionomic equilibrium. By symmetry all the fishermen are going to harvest the same quantity of fish. Therefore, $H(r)$ equals $n \times h_{i}(r)$. 
Figure 1: The Effects of an increase in the Fishing Fee

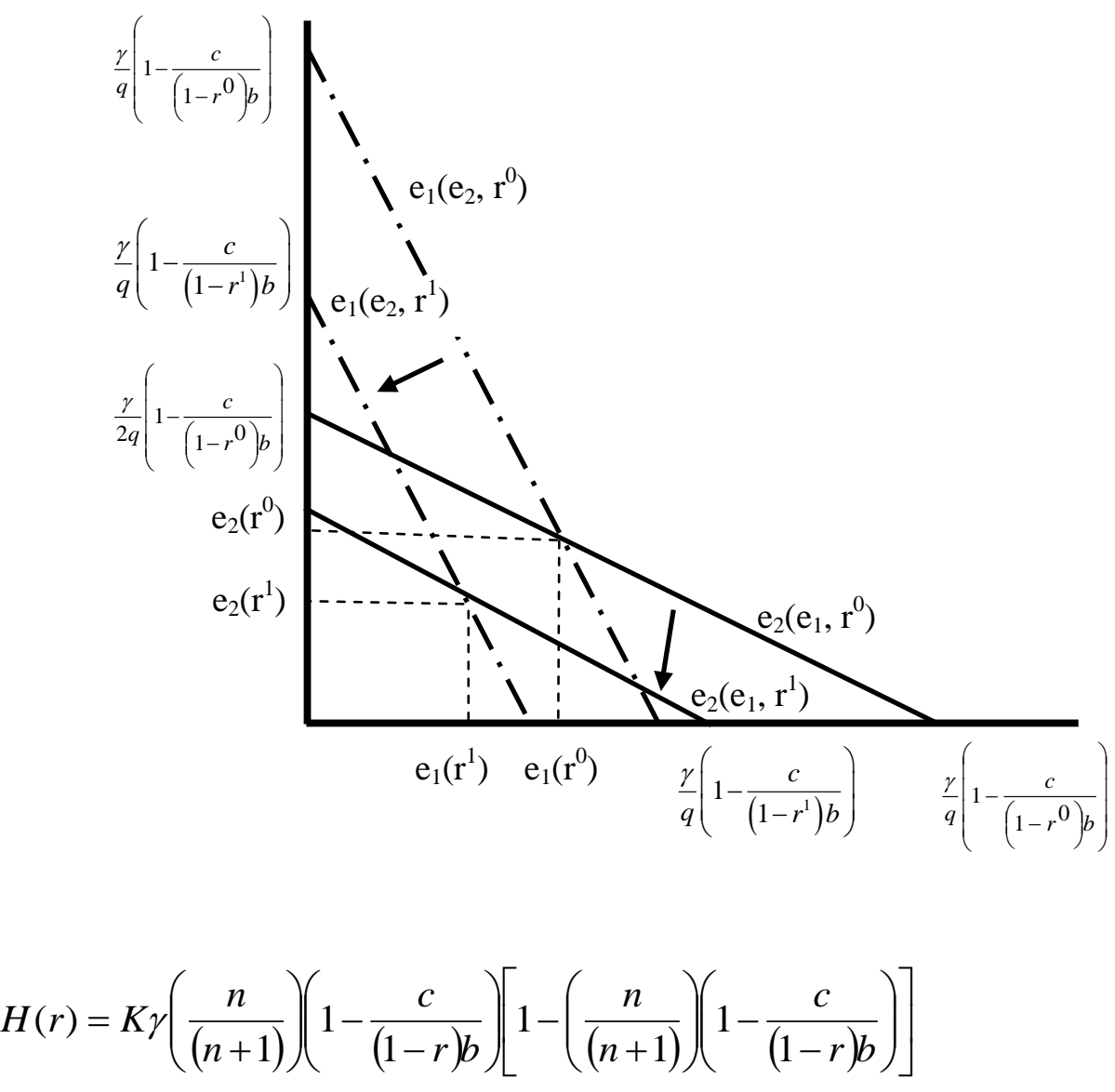

An increase in either the intrinsic rate of growth, $\gamma$, or the carrying capacity of the fishery, $\mathrm{K}$, will increase the amount of stock that can be removed from the fishery on a sustainable basis and would therefore increase the bionomic equilibrium harvest. From (0.11), an increase in the price of the species or a decrease in the marginal cost of effort will increase the total equilibrium effort. But since the increase in effort will reduce the size of the stock, the net effect on the bionomic equilibrium harvest is ambiguous.

The owner will attempt to maximize the revenue that it collects from the fishermen when the fishery reaches a bionomic equilibrium. The owner's revenue, $R(r)$, equals the revenue from the bionomic equilibrium harvest times the fishing fee. The owner's objective is to:

$$
\underset{r}{\operatorname{Max}} R=\operatorname{rpH}(r)
$$

Substituting (0.13) for the bionomic equilibrium harvest in (0.14):

$$
R(r)=r p \times K \gamma\left(\frac{n}{(n+1)}\right)\left(1-\frac{c}{(1-r) b}\right)\left[1-\left(\frac{n}{(n+1)}\right)\left(1-\frac{c}{(1-r) b}\right)\right]
$$


Note from (0.15) that the owner's revenue is continuous in r. Taking the derivative of the owner's objective function with respect to $r$ yields a polynomial of the third degree.

$R_{r}(r)=\frac{\left[b^{2}(r-1)^{3}+c^{2} n(1+r)-b c(n-1)(1-r)\right] n y}{q b(n+1)^{2}(r-1)^{3}}$

There is no closed solution for the revenue-maximizing fishing fee, $r^{*}{ }^{6}$ Nonetheless, it is straightforward to show that $\mathrm{r}^{*}$ exists.

Proposition 1: There exists at least one fishing fee, $r^{*}$, that maximizes the owner's revenue from the fishery. $r^{*}$ must be smaller than $r_{M A X}$ and strictly positive. $0<r^{*}<r_{M A X}$.

Proof: If the fishery owner does not charge a fishing fee, $r=0$, it will not collect any revenue. Similarly, if the owner sets $r$ equal to or higher than $r_{\text {MAX }}$ no fisherman will harvest from the fishery and the owner will not collect any revenue. If the owner sets $r$ anywhere between 0 and $r_{\text {MAX }}$ it will earn a positive amount of revenue since the total harvest is positive between these values and the owner retains a positive share of the revenue. Since R(r) is continuous in $r$, there must exist at least one fishing fee between 0 and $\mathrm{r}_{\mathrm{MAX}}$ that maximizes the owner's revenue.

Proposition 1 guarantees the existence of a revenue-maximizing fishing fee; however, it does not guarantee its uniqueness. The revenue-maximizing fee must be unique if the revenue function is globally concave with respect to $r$. The revenue function is globally concave with respect to $r$ if and only if its second-order derivative with respect to $r$ is negative. Taking the second-order derivative of (0.15):

$$
R_{r r}(r)=-\frac{3 c n[3 c n-(1-r)(n-1) b] K \gamma}{b^{2}(1+n)^{2}(r-1)^{4}}
$$

The condition that $n>b /(b-3 c)$, hereinafter the concavity condition, is sufficient to assure that the owner's revenue function is globally concave with respect to $r$ and that $r^{*}$ is unique. ${ }^{7}$ The concavity condition holds if $\mathrm{b} / \mathrm{c}<3$ or if the number of fishermen becomes infinitely large, $\mathrm{n}=\infty$.

Next, we investigate whether the fishing fee that the owner chooses is socially optimal. The socially optimal fishing fee is the fee that maximizes the net return from the fishery. In order to determine whether the fishing fee that the owner selects is socially optimal, we solve for the socially optimal fee and compare it to the revenue-maximizing fee.

The net return from the fishery, $\Pi$, equals the total revenue from the harvest minus the total cost of effort. The net return is composed of the total profit of the fishermen plus the owner's revenue. The total profit earned by the fishermen is $(1-r) \times b(1-q E / \gamma) E-c E$, where $E$ is the total effort exerted by the fishermen. The owner's revenue equals $r \times b(1-q E / \gamma) E$. Therefore:

$$
\Pi=b\left(1-\frac{q}{\gamma} E\right) E-c E
$$

Setting the derivative of $\Pi$ with respect to $E$ equal to zero, we find the total effort that will maximize the return from the fishery, $\hat{E}$, or the socially optimal effort. 


$$
\hat{E}=\frac{\gamma(b-c)}{2 q b}
$$

Let $\mathrm{E}(0)$ denote the total equilibrium effort that the fishermen exert in an unregulated fishery; that is, a fishery where $r=0$ and there are no other restrictions on the fishermen's behavior. By substituting 0 for $r$ in (0.11), we find that if $\mathrm{n}=1$ then $E(0)=\hat{E}$ and if $\mathrm{n}>1$ then $E(0)>\hat{E}$. These findings are consistent with other gametheoretical models of fishing conflicts (e.g., Levhari and Mirman, 1980; and Dockner et al, 1989), which conclude that when two or more fishermen compete over the same stock of fish they will exert more effort than is socially optimal. Since total equilibrium effort is decreasing in $\mathrm{r}$, there must exist a socially optimal fee, $\hat{r}$, such that $\hat{r}$ induces the fishermen to select $\hat{E}$. The fishing fee that the owner charges essentially acts as a tax by reducing the marginal benefit from effort for each of the fishermen. ${ }^{8}$ We find the socially optimal fee by setting (0.11) equal to $(0.19)$ and solving for $r$.

$$
\hat{r}=\frac{(b-c)(n-1)}{b(n-1)+c(n+1)}
$$

From (0.20), when several fishermen operate in the fishery, $\mathrm{n}>1$, then $0<\hat{r}<r_{M A X}$ and when a single fisherman operates in the fishery, $\mathrm{n}=1$, then the socially optimal fee is zero. An increase in the number of fishermen will increase the socially optimal fee. Essentially, the more intense the competition amongst the fishermen the more heavily they need to be taxed to prevent overexploitation.

The goal of the owner, however, is to maximize its revenue, not to maximize the net return from the fishery. Since both the total equilibrium effort and the bionomic equilibrium harvest are functions of $r$, the net return from a fishery can be written as a function of $r$. By imposing a fee, the owner determines both its revenue and the net return from the fishery in bionomic equilibrium.

$$
\Pi(r)=p H(r)-c E(r)
$$

Proposition 2: If the concavity condition holds, then the revenue-maximizing fishing fee must be higher than the socially optimal fishing fee, $r^{*}>\hat{r}$. Consequently, the total equilibrium effort exerted by the fishermen is lower than socially optimal.

Proof: First, we find the slope of the owner's revenue function at the socially optimal fee by substituting $(0.20)$ for $r$ in the first-order derivative of the owner's revenue function, equation $(0.16)$.

$$
R_{r}(\hat{r})=\frac{(b-c)[b(3 n-1)+c(n+1)]}{4 b^{2} n(n+1)}
$$

From (0.22), the owner's revenue function is strictly increasing at the socially optimal fee. Therefore, there must exist some higher fishing fee that yields higher revenue for the owner than the socially optimal fee. If the revenue function is globally concave with respect to $r$, then the revenue-maximizing fee must be higher than the socially optimal fee. ${ }^{9}$ If the socially optimal fee is higher than the revenue-maximizing fee, then total equilibrium effort must be lower than the socially optimal effort since total effort is decreasing in $\mathrm{r}$.

The revenue-maximizing fishing fee will always be larger than the maximum sustainable yield fee, $\mathrm{r}_{\mathrm{MSY}}$, defined as the fishing fee that maximizes the bionomic equilibrium harvest, regardless of whether the concavity condition holds or not. We solve for $\mathrm{r}_{\mathrm{MSY}}$ by setting the derivative of $\mathrm{H}(\mathrm{r})$, equation (0.13), with respect to $\mathrm{r}$ equal to zero and solving for $r$. 


$$
r_{M S Y}=\frac{b(n-1)-2 c n}{b(n-1)}
$$

As long as the concavity condition holds, then $r^{*}>\hat{r}>r_{M S Y}$ and $E\left(r_{M S Y}\right)>E(\hat{r})>E\left(r^{*}\right)$. The maximum sustainable yield fee may be positive or negative (which implies a subsidy). $\mathrm{r}_{\mathrm{MSY}}$, however, is always smaller than the socially optimal fee as can be seen by comparing (0.23) and (0.20). These relationships are drawn in Figure 2, which shows the net return and the owner's revenue that result from different levels of total equilibrium effort. ${ }^{10}$ Figure 2 is similar to the one developed by Schaefer (1957), but it also incorporates the fact that the total equilibrium effort is a function of the fishing fee.

Figure 2: Revenue and Net Return as a Function of $r$

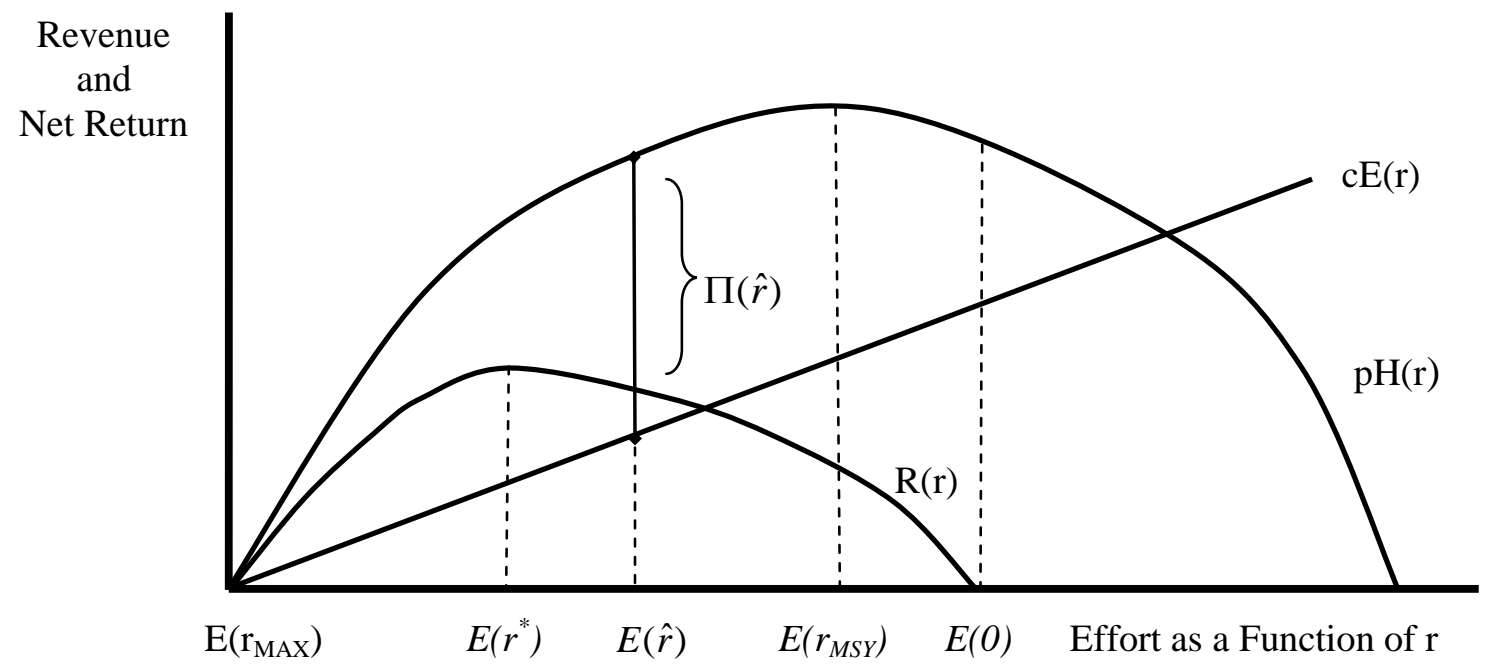

Our analysis suggests than if more than one fisherman operates in a fishery, the fishery owner can increase the net return from the fishery by charging the fishermen a fishing fee. However, if the goal of the owner is to maximize the revenue that it receives from the harvest it will select a fishing fee that is higher than socially optimal. ${ }^{11}$ Under some circumstance the fee that the owner chooses may reduce the net return from the fishery below the level that it was when the fishery was unregulated. The most obvious case occurs when only one fisherman operates in the fishery. As previously shown, if the fishery is unregulated $(r=0)$, then a single fisherman will select the level of effort that maximizes the net return from the fishery. However, since the owner charges the fisherman a fee (as it must to earn revenue), the fisherman will lower its effort below the socially optimal level, resulting in a decrease in net return. Since H(r) and E(r) are both continuous in $n$, then the net return from the fishery, $\mathrm{pH}(\mathrm{r})$ $\mathrm{cE}(\mathrm{r})$, is continuous in $\mathrm{n}$. Consequently, if $\mathrm{n}$ is sufficiently small, then the owner reduces the net return from the fishery by charging a fishing fee.

\section{Extensions of the Base Model}

In the previous section we assumed that the number of fishermen that operate in the fishery is exogenous and that the owner only charges a fishing fee. As recognized by others (Clark and Munro 1987, 1991; and Raissi 2001), the fishery owner is not be able to simultaneously maximize its revenue and the net return from the fishery under these circumstances. In fact, the owner charges a fee that is too high causing the fishermen to exert less effort than is socially optimal. In this section we consider two ways in which the owner may be able to simultaneously maximize its revenue and the net return from the fishery. First, we consider the case in which the owner can determine both the number of fishermen and the fishing fee but does not charge an entry fee. The Extended Fisheries 
Jurisdiction gives coastal nations the right to determine the number of fishermen that operate in their Exclusive Economic Zones but long-term agreements may prevent them from charging an entry fee. Then, we consider the case in which the owner can use a two-tier tariff, which consists of an entry fee and a fishing fee.

Suppose that the fishery owner can choose both the number of fishermen and the fishing fee that each fisherman must pay but does not charge an entry fee. Consider the following two-stage game. In the first stage, the owner determines the number of fishermen, $\mathrm{n}$, and the fishing fee that each of them must pay, $\mathrm{r}$. In the second stage, the fishermen that are permitted to operate in the fishery, having observed $\mathrm{n}$ and $\mathrm{r}$, simultaneously choose their levels of effort in order to maximize their profit.

We solve for the number of fishermen and the fishing fee that the owner selects in subgame perfect Nash equilibrium. Equation (0.9) can be rewritten to show the equilibrium effort that a given fisherman i selects in the second stage of the game, $e_{i}(n, r)$, given the $n$ and $r$ that the owner chooses in the first stage of the game. Hereinafter, we write the fishermen's equilibrium efforts and the owner's revenue as a function of $n$ and $r$ since both of these variables are assumed to be determined by the owner. An increase in the number of fishermen would reduce the effort that each of the fishermen exerts in subgame perfect Nash equilibrium as can be seen by taking the derivative of (0.9) with respect to $n$.

$e_{n}(r, n)=-\frac{\gamma}{q(n+1)^{2}}\left(1-\frac{c}{(1-r) b}\right)<0$

Although each fisherman reduces its effort as $n$ increases, the total equilibrium effort, $E(n, r)$, rises as $n$ increases, as can be seen by taking the derivative of $(0.11)$ with respect to $\mathrm{n}$. The increase in total equilibrium effort intensifies the strain on the stock. As a result, the bionomic equilibrium stock decreases as $\mathrm{n}$ increases, as can be seen by taking the derivative of $(0.12)$ with respect to $n$.

$$
\bar{x}_{n}(r, n)=-\frac{K}{(n+1)^{2}}\left(1-\frac{c}{(1-r) b}\right)<0
$$

By assumption, the fishermen's harvest is determined by a CPUE production function, equation (0.3). Since an increase in $\mathrm{n}$ causes each fisherman to reduce its effort and also leads to a reduction in the bionomic equilibrium stock, it must reduce the harvests that each fisherman removes from the fishery. The net effect of an increase in $\mathrm{n}$ on the bionomic equilibrium harvest, however, depends on the values of the parameters, as can be seen by taking the derivative of $(0.13)$ with respect to $n$ :

$$
H_{n}(r, n)=\frac{\gamma K(b(1-r)-c)[2 c n-b(n-1)(1-r)]}{(1+n)^{3} b^{2}}
$$

The owner's revenue equals $\mathrm{rp} \times \mathrm{H}(\mathrm{n}, \mathrm{r})$. Therefore, in order to maximize its revenue the owner selects the number of fishermen that will maximize the bionomic equilibrium harvest. $\mathrm{H}_{\mathrm{n}}(\mathrm{r}, \mathrm{n})$ is positive as long as $2 \mathrm{cn}>\mathrm{b}(\mathrm{n}-$ 1) $(1-r)$, a condition that holds true for any feasible values of $n$ and $r$ if $b / c<2$. If $b / c<2$, then the owner would admit as many fishermen into the fishery as possible. The owner could do so by not placing any restrictions on entry to the fishery, since as long as the fishery is exploitable it is profitable for additional fishermen to enter the fishery regardless of what $\mathrm{n}$ is. Thus, if the owner does not restrict entry to the fishery, then the number of fishermen would become infinitely large. We refer to the outcome in which the owner does not restrict entry to the fishery as the open access solution.

We solve for the profit of fisherman $\mathrm{i}, \Pi_{\mathrm{i}}$, by substituting (0.9) for $\mathrm{e}_{\mathrm{i}}$ and $(0.12)$ for $\bar{x}(r)$ into the fisherman's profit function, equation (0.6), and simplifying. 


$$
\begin{aligned}
& \Pi_{i}(n, r)=\frac{[b(1-r)-c]^{2} \gamma}{b q(n+1)^{2}(1-r)} \quad \text { if }(1-r) b>c \\
& 0 \text { otherwise }
\end{aligned}
$$

Note from (0.27) that as $\mathrm{n}$ approaches infinity, $\Pi_{\mathrm{i}}$ approaches zero. Therefore, none of the fishermen earns any profit under open access as asserted by Gordon (1954) and others. ${ }^{12}$

The owner will not restrict entry to the fishery if $b / c<2$. But will the owner restrict entry to the fishery if $\mathrm{b} / \mathrm{c} \geq 2$ ? To answer this question, consider the owner's objective function. The owner maximizes its revenue by choosing $\mathrm{n}$ and r. Rewriting (2.15):

$$
\underset{n, r}{\operatorname{MAX}} R(n, r)=r p \times K \gamma\left(\frac{n}{(n+1)}\right)\left(1-\frac{c}{(1-r) b}\right)\left[1-\left(\frac{n}{(n+1)}\right)\left(1-\frac{c}{(1-r) b}\right)\right]
$$

The first-order conditions of the owner's maximization problems are:

$$
\begin{aligned}
& R_{n}(n, r)=\frac{[b(1-r)-c][2 c n-b(n-1)(1-r)] r \gamma}{q b(1+n)^{3}(r-1)^{2}}=0 \\
& R_{r}(n, r)=\frac{\left[b^{2}(r-1)^{3}+c^{2} n(1+r)-b c(n-1)(1-r)\right] n y}{q b(n+1)^{2}(r-1)^{3}}=0
\end{aligned}
$$

If $2 c>b(1-r)$, then the derivative of the revenue function with respect to $n$ is positive for any $n$, which implies that the owner should choose the open access solution. Rearranging $(0.29)$ to solve for $\mathrm{n}$ :

$$
\begin{array}{cc}
n(r)=\frac{b(1-r)}{b(1-r)-2 c} & \text { if } 2 c<b(1-r) \\
\infty & \text { if } 2 c \geq b(1-r)
\end{array}
$$

Consider the possibility that the $\mathrm{n}$ that maximizes the owner's revenue is some finite number. If this were the case, we could solve for the $n$ and $r$ that the owner would choose in subgame perfect Nash equilibrium by simultaneously solving the first-order conditions. Substituting (0.31) into (0.30) yields several possible values for $r$.

$$
r=0, \frac{b-c}{b}, \frac{b-c+\sqrt{2} c}{b}, \frac{b-c-\sqrt{2} c}{b}, \frac{b-c}{b+c}
$$

Let us examine which one of these values of $\mathrm{r}$ maximizes the owner's revenue. Clearly $\mathrm{r}$ cannot equal zero. If it did the owner would not earn any revenue. $(b-c) / b$ equals $r_{\text {MAX }}$ and $(b-c+2.5 c) / b$ is larger than $r_{\text {MAX. If the }}$ owner selects either of these values for $r$, then the fishermen would not exert any effort and the owner will not earn any revenue. Thus, the only possible values for $r$ in subgame perfect Nash equilibrium are $r^{\prime}$, where $r^{\prime}=(b-c-$ $\left.2^{.5} \mathrm{c}\right) / \mathrm{b}$, and $\mathrm{r}_{\mathrm{OA}}$, where $\mathrm{r}_{\mathrm{OA}}=(b-c) /(b+c)$. As we shall show later, $\mathrm{r}_{\mathrm{OA}}$ is the fee that the owner selects under open 
access. We determine the number of fishermen that the owner would select when choosing r', n', by substituting r' for $r$ in $(0.31)$ and simplifying.

$n^{\prime}=\frac{b(1+\sqrt{2})+c(7+5 \sqrt{2})}{b(\sqrt{2}-1)+c(\sqrt{2}+1)}$

Substituting n' and r' back into the owner's revenue function, equation (0.28), and simplifying:

$R\left(n^{\prime}, r^{\prime}\right)=\frac{[b(1+\sqrt{2})+c(7+5 \sqrt{2})(b-(1+\sqrt{2}) c)] \gamma}{2 \sqrt{2}[(2+\sqrt{2}) b+(10+7 \sqrt{2}) c] q}$

Substituting $\mathrm{r}_{\mathrm{OA}}$ into (0.29) yields that $\mathrm{n}$ equals infinity. From (0.28), we determine the limit of the owner's revenue function as $\mathrm{n}$ approaches infinity, $\mathrm{R}(\infty, \mathrm{r})$.

$$
R(\infty, r)=r p \times K \gamma\left(1-\frac{c}{(1-r) b}\right)\left(\frac{c}{(1-r) b}\right)
$$

Substituting $r_{\mathrm{OA}}$ for $r$ in (3.5) gives the owner's revenue under the open access solution. We are now ready to show that if the owner does not charge an entry fee it would choose the open access solution.

$R\left(\infty, r_{O A}\right)=\frac{(b-c)^{2} b \gamma}{4 b^{2} q}$

Proposition 3: If the fishery owner can determine both the fishing fee and the number of fishermen that operate in its fishery but does not charge an entry fee, then it does not restrict access to the fishery and chooses a fishing fee of $r_{O A}$, where $r_{O A}=(b-c) /(b+c)$.

Proof: Suppose that the owner selects the open access solution by setting $\mathrm{n}=\infty$. Equation $(0.35)$ shows the owner's revenue as a function of $r$ as $n$ converges to infinity. Taking the derivate of (0.35) with respect to $r$ and setting it equal to zero shows that the fishing fee that maximizes the owner's revenue under open access is $r_{\mathrm{OA}}$, where $r_{\mathrm{OA}}=(b-c) /(b+c)$. Therefore, if the owner selects the open access solution it will set $r=r_{O A}$. We previously demonstrated that if an interior solution exists, then the only feasible solution is for the owner to set $r=r^{\prime}$ and set $n$ $=n^{\prime}$. However, selecting the open access solution always yields more revenue for the owner than selecting ( $\left.n^{\prime}, r^{\prime}\right)$, as can be seen by subtracting $R\left(n^{\prime}, r^{\prime}\right)$ from $R(\infty, r)$.

$$
R\left(\infty, r_{O A}\right)-R\left(n^{\prime}, r^{\prime}\right)=\frac{b c\left[\sqrt{2} b^{2}+2(3+2 \sqrt{2}) b c+(10+7 \sqrt{2}) c^{2}\right] \gamma}{4 b^{2}[(\sqrt{2}+\sqrt{2}) b+(10+7 \sqrt{2}) c] q}
$$

The right-hand side of (0.37) is positive for any feasible values of $\mathrm{c}, \mathrm{p}, \mathrm{q}, \mathrm{K}$ and $\gamma$. Therefore, selecting the open access solution always yields more revenue for the owner than selecting (n', r'). Since (n', r') is the only feasible interior solution, then setting $n=\infty$ and $r=r_{O A}$ yields more revenue for the owner than any other combination of $\mathrm{n}$ and $\mathrm{r}$. 
The fishing fee that the owner selects under open access, $\mathrm{r}_{\mathrm{OA}}$, increases with increases in either the price of the species, the carrying capacity of the fishery or the catchability coefficient (recall that $b=p q K$ ) and decreases with increases in the marginal cost of effort. Proposition 3 shows that the open access solution maximizes the owner's revenue, but is the open access solution socially optimal?

Proposition 4: The open access solution, in which the owner does not restrict entry to the fishery and charges a fishing fee of $r_{O A}$, is socially optimal since it maximizes the net return from the fishery.

Proof: A socially optimal solution will induce fishermen to select the socially optimal effort, $\hat{E}$, defined in (0.19). From (0.11), the total equilibrium effort will converge to $[\gamma(1-r) b-\gamma c] /[(1-r) b q]$ when $n$ converges to infinity. If the owner charges a fee of $\mathrm{r}_{\mathrm{OA}}$, then the total equilibrium effort exerted by the fishermen under the open access solution, $\mathrm{E}\left(\infty, \mathrm{r}_{\mathrm{OA}}\right)$, equals:

$$
E\left(\infty, r_{O A}\right)=\frac{\gamma(b-c)}{2 q b}
$$

The total equilibrium effort under the open access solution with $r=r_{O A}$ is identical to the socially optimal effort. Thus, the fishermen will select the level of effort that maximizes the net return from the fishery under the open access solution.

Under open access, fishermen earn just enough revenue, after paying the fishing fee, to cover their cost and the owner collects all the net return from the fishery via a fishing fee. Therefore, the owner has the incentive to maximize the net return from the fishery and does so by selecting a fee that induces fishermen to choose the socially optimal total equilibrium effort. Under the open access solution, the owner simultaneously maximizes its own revenue and the net return from the fishery.

Allowing open access to the fishery is not the only way for the fishery owner to simultaneously maximize its revenue and the net return from the fishery. The owner could also use a two-tier tariff by charging each fisherman an entry fee and then levying a fishing fee on their harvest. Since the fishermen will continue to harvest as long as their economic profit is not negative, the owner can set the entry fee to any amount that is equal to or is smaller than the fishermen's profit. If the owner sets the entry fee equal to the fishermen's profit, the fishermen will not make any profit and the owner will extract all the net return from the fishery. Therefore, the revenue-maximizing entry fee, $\tau^{*}$, for a given $r$ and $n$, is:

$$
\tau^{*}(n, r)=\prod_{i}\left(r^{*}(n), n\right)
$$

Both the revenue-maximizing fishing fee and the revenue-maximizing entry fee are a function of $n$. From $(0.20)$, as the number of fishermen increases so does the revenue-maximizing fishing fee. On the other hand, if the owner admits more fishermen it would decrease the entry fee of each fisherman since the profit of each fisherman would decrease.

Thus, the owner can admit any number of fishermen, $\mathrm{n}$, and the select the corresponding combination of $r^{*}(n)$ and $\tau^{*}(n)$. If the owner increases $n$, it would also increase $r^{*}(n)$ and decrease $\tau^{*}(n)$. In general, the larger $n$ the more revenue the owner makes from the fishing fee and the less revenue it makes from the entry fee. ${ }^{13}$ The open access solution is therefore one of an infinite number of possible solutions. Under open access, the owner does not charge an entry fee, since the fishermen do not make any profit, and extracts all the rent via a fishing fee.

\section{Concluding Remarks}

The Extended Fisheries Jurisdiction was adopted primarily to accomplish two objectives: to improve the management of the world's marine resources and to provide an economic resource for developing coastal nations. 
The Clarke and Munro model states that if a coastal nation permits foreign fishermen to operate in its fishery in exchange for a fishing fee, it generally cannot simultaneously maximize its revenue and the net return from the fishery. However, we show that the fishery owner can accomplish both of these objectives either by not restricting entry to its fishery or by using a two-tier tariff.

The Clarke and Munro model only considers the case in which a coastal nation charges a fishing fee and a tax (or subsidy) on effort, but does not determine the number of fishermen or charge an entry fee. We find that if the coastal nation cannot choose the number of fishermen or charge an entry fee it would charge a fishing fee that is too high causing fishermen to exert less effort than is socially optimal. Thus, when coastal nations permit foreign exploitation, nationalizing previously unregulated fisheries can potentially lead fishermen who were previously over-fishing a stock to under-fish it. In fact, we show that when the number of fishermen is exogenous and sufficiently small, the coastal nation may reduce net return below the level that it was when the fishery was not regulated. Furthermore, McKelvey (2002) shows that if a Distant Water Fishing Nations (DWFN) has to compete with a coastal nation over a straddling (migrating) stock it would harvest the stock more intensely then if it did not have to compete over the stock. Thus, nationalize fisheries may not always improve welfare. Though, there is some evidence that efficiency increases under the management of developing nations (e.g. Bulte et al, 1995).

Realistically, however, a coastal nation can choose the number of fishermen that operate in its fisheries and charge them an entry fee. If a coastal nation can choose the number of fishermen it can permit open access to its fisheries, which will drive down the fishermen's profit to zero and allow the coastal nation to extract all the net return from the fishery. Alternatively, the coastal nation can use a two-tier tariff, charging fishermen an entry fee and an additional fishing fee, in order to extract all the net return from the fishery.

Our model does not provide a clear answer as to how many fishermen a coastal nation should admit into its fisheries. In fact, there are infinite combinations of entry fees and fishing fees that maximize the owner's revenue. Nonetheless, there are several considerations that may influence the owner's decision. There are several reasons, which are not modeled in this paper, why a coastal nation may wish to restrict the number of fishermen that operate in its EEZ. First, the owner may engage in domestic exploitation of the fishery. Charles (1986) shows that if the domestic fleet has an inferior technology the owner has to restrict the number of foreign fishermen in order not to drive domestic fishermen out. Second, the owner may be concerned about spillover externalities that may occur if it admits a large number of fishing vessels into its EEZ. Finally, the owner's monitoring and enforcement costs may increase as the number of fishermen rise.

On the other hand, a coastal nation, especially a developing nation with little political clout, may not want to admit too few fishermen into its EEZ for fear that they would wield too much monopsony power. In fact, in order to efficiently sell out licenses for the use of a fishery, the owner must have some competition amongst the fishermen. Hence, a fishery owner would not want to admit too many or too few foreign fishermen into the fishery. For instance, the Parties to the Nauru Agreement (a group of island nations in the South West Pacific Ocean) supply a limited number of licenses to each DWFN that operates fishing vessels within their EEZ and contiguous areas (Lodge, 1998). Future research can further investigate what is the optimal number of fishermen that a coastal nation should admit into its fisheries.

I would like to thank participants at the International Applied Business Research Conference in San Juan, Puerto Rico and the International Institute of Fisheries Economics \& Trade Conference in Wellington, New Zealand for their comments. I am also grateful for Samuel Pooley for his helpful suggestions.

\section{References}

1. Berck, Peter and Jeffrey M. Perloff. 1984. "An Open-Access Fishery with Rational Expectations." Econometrica, 52(2): 489-506.

2. Bulte, Erwin, Henk Folmer and Wim Heijman. 1995. "Open Access, Common Property and Scarcity Rent in Fisheries." Environmental and Resource Economics, 6(4): 309-20. 
3. $\quad$ Campbell, H. F. 1996. "Prospects for an International Tuna Resource Cartel." Marine Policy, 50(5): 41927.

4. Charles, Anthony T. 1986. "Coastal State Fishery Development: Foreign Fleets and Optimal Investment Dynamics." Journal of Development Economics, 24(2): 331-58.

5. Clark, Colin W. and Gordon R. Munro. 1975. "The Economics of Fishing and Modern Capital Theory: A Simplified Approach.” Journal of Environmental Economics and Management, 2: 92-106.

6. Clarke, Francis H. and Gordon R. Munro. 1987. "Coastal States, Distant Water Fishing Nations and Extended Jurisdiction: A Principal-agent Analysis." Natural Resource Modeling, 2(1): 81-107.

7. Clarke, Francis H. and Gordon R. Munro. 1991. "Coastal States and Distant Water Fishing Nations: Conflicting Views of the Future." Natural Resource Modeling, 5(3): 345-69.

8. Dockner, Engelbert, Gustav Feichtinger and Alexander Mehlmann. 1989. "Non-cooperative Solutions for a Differential Game Model of Fishery." Journal of Economic Dynamics and Control, 13(1): 1-20.

9. Fischer, Ronald D. and Leonard J. Mirman. 1996. "The Compleat Fish Wars: Biological and Dynamic Interactions.” Journal of Environmental Economics and Management, 30(1): 34-42

10. Gordon, Scott H. 1954. "The Economic Theory of Common Property Resources: The Fishery." Journal of Political Economy, 62: 124-42.

11. Gopalakrishnan, Chennat. 1989. "Transnational Corporations and Ocean Technology Transfer: New Economic Zones Are Being Developed by Public/Private Partnerships but Deep Sea Miners Balk on Royalties." American Journal of Economics and Sociology, 48(3): 373-83.

12. Ishimine, Tomotaka. 1978. "The Law of the Sea and Ocean Resources." American Journal of Economics and Sociology, 37(2): 129-44.

13. Kaitala, Veijo and Gordon R. Munro. 1993. "The Management of High Seas Fisheries." Marine Resource Economics, 8(4): 313-29.

14. Kamien, Morton, David Levhari and Leonard J. Mirman. 1985. "Dynamic Model of Fishing: The Relationship to Conjectural Variations." Journal of Environmental Economics and Management, 12(4): 308-21.

15. Koh, Tommy T. B. 1983. "The Third United Nations Conference on the Law of the Sea: What Was Accomplished?" Law and Contemporary Problems, 46(2): 5-9.

16. Levhari, David and Leonard J. Mirman. 1980. "The Great Fish War: An Example Using a Dynamic Cournot-Nash Solution." Bell Journal of Economics: 11(1): 322-34.

17. Lodge, Michael. 1998. "The Development of the Palau Arrangement for the Management of the Western Pacific Purse Seine Fishery,” Marine Policy, 22(1): 1-28.

18. McKelvey, Robert W., Leif K. Sandal and Stein I. Steinshamn. 2002. "Fish Wars on the High Seas: A Straddling Stock Competition Model.” International Game Theory Review, 4(1): 53-69.

19. Munro, Gordon R. 1982. "Fisheries, Extended Jurisdiction and the Economics of Common Property Resources." Canadian Journal of Economics, 15(3): 405-25.

20. Raissi, N. 2001. "Features of Bioeconomics Models for the Optimal Management of a Fishery Exploited by Two Different Fleets." Natural Resource Modeling, 14(2): 287-310.

21. Rosenman, Robert E. 1986. "The Optimal Tax for Maximum Economic Yield: Fishery Regulation under Rational Expectations." Journal of Environmental Economics and Management, 13(4): 348-62.

22. Ruseski, Goradz. 1998. International Fish Wars: The Strategic Roles for Fleet Licensing and Effort Subsidies. Journal of Environmental Economics and Management, 36(1): 70-88.

23. Schaefer, Milner B. 1957. "Some Considerations of Population Dynamics and Economics in Relation to the Management of Marine Fisheries." Journal of Fisheries Research Board of Canada, 14: 669-81.

24. Scott, Anthony. 1955. "The Fishery: the Objective of Sole Ownership." Journal of Political Economy, 63: $116-24$.

\footnotetext{
${ }^{1}$ See Koh (1983) for particular on the United Nations Conference on the Law of the Sea.

${ }^{2}$ See Charles (1986) for more examples.

${ }^{3}$ The total harvest, $\mathrm{H}$, can never exceed the size of the stock, $\mathrm{H} \leq \mathrm{x}$. Since the fishermen are identical then the total harvest equals $n \times h_{i}(e)$, which implies that $n \times q \times e_{i} \leq x$. Rearranging, if $e_{i} \geq 1 / n q$ then the entire stock will be evenly
} 
split amongst the fishermen and the species will be driven to extinction. Since the fishermen do not discount future returns by assumption, they would never want to drive the species to extinction. If they drove the stock to extinction they would be giving up an infinite streams of positive returns from the fishery.

${ }^{4}$ A dynamic model may be too complex to analyze the two-stage, multivariate, $\mathrm{n}+1$ agents game proposed here. Munro (1982) provides a brief discussion on the use of static versus dynamic models. For examples of dynamic models see Kamien et al (1985) and Clark and Munro (1975).

${ }^{5}$ Other papers that examine the strategic interactions between a coastal nation and the fishermen that operate in its fishery (e.g., Clark and Munro 1987, 1991; and Raissi, 2001) also assume that the price of the species and the marginal cost of effort are constant and identical for all the fishermen.

${ }^{6}$ Solving for the revenue-maximizing fishing fee yields a system of one real root and two complex roots. The real root is:

$r=1-\frac{3^{2 / 3} c[b(n-1)+c n]}{3\left[-9 b^{4} c^{2} n+\phi\right]^{1 / 3}}-\frac{3^{1 / 3}\left[-9 b^{4} c^{2} n+\phi\right]^{1 / 3}}{3 b^{2}}$

Where

$\phi=\sqrt{3} \sqrt{b^{6} c^{3}\left[27 b^{2} c n^{2}+(b(n-1)+c n)^{3}\right]}$

${ }^{7}$ If the concavity condition does not hold, then $\mathrm{r}^{*}$ may or may not be unique, depending on the shape of the owner's revenue function.

${ }^{8}$ See Rosenman (1986) for a discussion on optimal taxation in fisheries exploitation.

${ }^{9}$ If the revenue function is not globally concave with respect to $r$, it may be possible that the socially optimal fee is lower than some other local maximum fee but higher than the revenue-maximizing fishing fee (the global maximum fee).

${ }^{10}$ We draw $\mathrm{E}(0)$, the total equilibrium effort that is chosen when $\mathrm{r}=0$, as larger than $\mathrm{E}\left(\mathrm{r}_{\mathrm{MSY}}\right)$. However, $\mathrm{E}(0)$ can be larger than, smaller than or equal to $\mathrm{E}\left(\mathrm{r}_{\mathrm{MSY}}\right)$, depending on the values of the parameters.

${ }^{11}$ Although we can not prove that the revenue-maximizing fee is higher than the socially optimal fee when the concavity condition does not hold, after comparing $\mathrm{r}^{*}$ and $\hat{r}$ under many different feasible values of the parameters we are convinced that this is always the case.

${ }^{12}$ Berck and Perloff (1984) show that a fishery converges to the same equilibrium under rational expectations as under myopic expectations, which were considered by Gordon (1954); although, the paths of adjustment differ.

${ }^{13}$ We reserve the simple proof of this statement to the reader. 